\title{
Blood, Urine, and Breath Levels After Rapid Intravenous Infusion of Ethanol
}

\author{
J. W. DUNDEE, ${ }^{*}$ M.D., PH.D., F.F.A.R.C.S. ; J. W. D. KNOX, † M.B., F.F.A.R.C.s. ; M. ISAAC, $\ddagger$ M.D., D.A., PH.D.
}

\begin{abstract}
ummary: A re-evaluation of alcohol as an intravenous $N$ anaesthetic provided an opportunity of studying the changes in venous blood, urine, and breath levels under controlled conditions. Twelve volunteer patients were given $0.8 \mathrm{~g} . / \mathrm{kg}$. in $8 \% \mathrm{w} / \mathrm{v}$ solution over four to six minutes. Despite standardization of technique there was a great variation in the peak urinary concentration and also some variation in the time at which urinary level exceeded that of blood, but this latter always occurred within 30 minutes of infusion. From one hour after infusion there was a constant mean rate of decline of both venous and urinary concentrations. While urinary/venous blood ratios varied greatly they remained fairly constant in each individual patient. The average ratio (1.35) was similar to that of other published papers. With a modification of gearing $(58: 1$ to $67: 1)$ the standard Ethanographe gave good correlation of breath with venous blood concentrations at low levels when patients were able to operate the machine themselves. At high levels, however, with a two-minute period of rebreathing in the unconscious patient, the correlation was poor.
\end{abstract}

\section{Introduction}

Recent road traffic legislation has aroused interest in blood, breath, and urine alcohol levels, particularly the relationship of these to each other. In the initial Road Safety Act of 1962 the venous blood level could be derived from that obtained in urine by using a conversion factor. This, however, has now been amended, and the 1967 Road Safety Act gives a lower "prescribed limit" of $80 \mathrm{mg}$. of alcohol per $100 \mathrm{ml}$. of blood or $107 \mathrm{mg}$. of alcohol in $100 \mathrm{ml}$. of urine and abolished the significance of the conversion ratio in which venous blood levels can be derived from that found in urine.

Apart from the clinical investigations of Gostomzyk, Dilger, and Dilger (1969) and Gostomzyk and Streffer (1969), who did not carry out urinary or breath analyses, most pharmacokinetic studies have been made after oral ingestion of alcohol. The reassessment of dilute ethanol as a general anaesthetic provided an opportunity for the simultaneous study of blood, breath, and urinary alcohol concentration in samples taken at any desired time over four to six hours under controlled conditions. The changes in arterial and venous blood levels immediately after infusion and the rate of plasma decay after moderate $(0.8 \mathrm{~g} . / \mathrm{kg}$.) and large $(1.2 \mathrm{~g} . / \mathrm{kg}$.) doses of alcohol have already been reported by Dundee (1970) and by Dundee, Isaac, and Taggart (1970). The present study concerns the relationship between venous blood, urinary, and alveolar air alcohol concentrations, and was carried out on 12 fit patients whose permission for sampling had been obtained.

\section{Anaesthesia}

This has been described fully elsewhere (Dundee, Isaac, Pandit, and McDowell, 1970) and will only be summarized here. Following atropine/diazepam premedication, up to 500 $\mathrm{ml}$. of $8 \%(\mathrm{w} / \mathrm{v})$ alcohol in solution compound lactate sodium

\footnotetext{
- Professor of Anaesthetics.

+ Senior Tutor/Senior Registrar in Anaesthetics.

\$ Research Fellow. Department of Anaesthetics, the Queen's University of Belfast, Northern
Ireland.
}

B.P. (Hartmann's) was infused over four to six minutes as required to induce sleep, and anaesthesia was continued with nitrous oxide and oxygen. Operations lasted up to 10 minutes and recovery occurred a few minutes after discontinuing the nitrous oxide.

In about half the patients $300-500 \mathrm{ml}$. of $5 \%$ dextrose in water or a balanced salt solution was infused over a 10-minute period before the administration.

\section{Method of Study}

Studies were carried out on patients scheduled for minor gynaecological operations who required catheterization-for surgical reasons. The nature of the investigation was explained to them and consent obtained to allow the catheter to remain in situ for up to six hours after operation.

Patients were asked to empty the bladder for induction, and a self-retaining catheter was inserted immediately consciousness was lost. Venous blood from the forearm not used for infusion and simultaneous urine samples were taken at 4, $7 \frac{1}{2}, 15,22,30,45$, and 60 minutes after infusion and then at half-hour intervals for up to five hours. During the latter samples the bladder was emptied five minutes before the sample was taken.

Blood samples were immediately placed in glass bottles containing sodium fluoride and calcium oxalate as a preservative, while urine was placed in a sealed plastic container. Samples were stored at $4^{\circ} \mathrm{C}$. until the alcohol content was later analysed by gas chromatography with the Perkin Elmer model F 11 flame ionization gas chromatograph.

Breath samples were taken after a two-minute rebreathing period (with only a basal oxygen flow of $200-300 \mathrm{ml} . /$ minute) into a 2-litre bag situated at the facemask. These were discharged immediately into a recalibrated Ethanographe (Etzlinger, Geneva) as currently used in Northern Ireland. The procedure for transfer and analysis of the sample was carried out as for routine police use of the machine (Borkenstein and Smith, 1961; Noordzij, 1969). The corresponding venous blood sample was drawn after one minute of rebreathing. After anaesthesia breath analysis could not again be carried out until the patient was fully co-operative and able to blow directly into the machine. This was never less than one hour after the end of anaesthesia.

In 9 of the 12 patients a complete set of samples was obtained for up to 270 minutes with a variable amount of data in the other three.

\section{Results}

Blood and urine data are discussed first.* Despite standardization of the procedure so far as was possible there was considerable individual variation in the pattern of urinary levels during the first hour after infusion. The equilibrium venous concentration (sample taken four minutes after infusion at the time when arteriovenous equilibrium has occurred) was fairly constant (160-235 mg./100 ml.). The highest urinary concentration reached, however, ranged from 120 to $258 \mathrm{mg} . / 100 \mathrm{ml}$. and the time of its occurrence was also very variable. The urinary/venous blood ratio at the time of peak ethanol level varied from 1.07 to 2.24 . There was less variation in the estimated time (obtained from free-hand graph of readings) at which the urinary and blood concentra*Detailed data can be obtained from Professor J. W. Dundee. 
tions crossed over, this being within the first half-hour of the end of the infusion in all but one patient.

The mean values in the 10 patients in whom complete data were obtained are shown in Fig. 1. There was a constant average decay rate for both venous blood and urinary levels within half an hour of the cross over of these levels. Even in these patients, however, there was a considerable variation in the urinary/venous blood ratio (Fig. 2). There was a suggestion that this may have increased somewhat after 240 minutes, but the number of patients was too small to be certain of this. The values for the total 97 observations in this figure gave an average of $1.35 \pm 0.015$ (range 1.07-1.98).

On inspection of data it was observed that while there was a scatter of urinary/venous blood ratios these remained fairly constant in any one patient between 60 and 240 minutes after infusion (Fig. 3). Those patients who were given an intravenous infusion before the alcohol did not have a lower ratio than those without fluid. If the urinary/venous blood

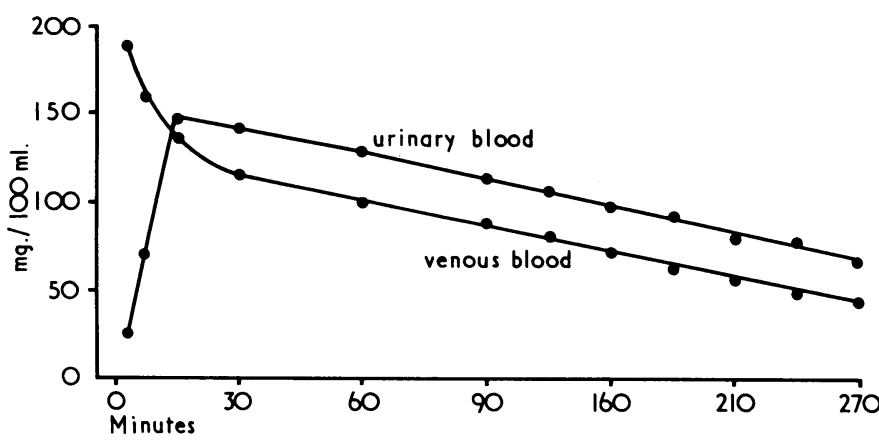

F1G. 1.-Mean venous blood and urinary blood ethanol concentrations at varying times after rapid intravenous infusion of ethanol $0.8 \mathrm{~g} . / \mathrm{kg}$. of body

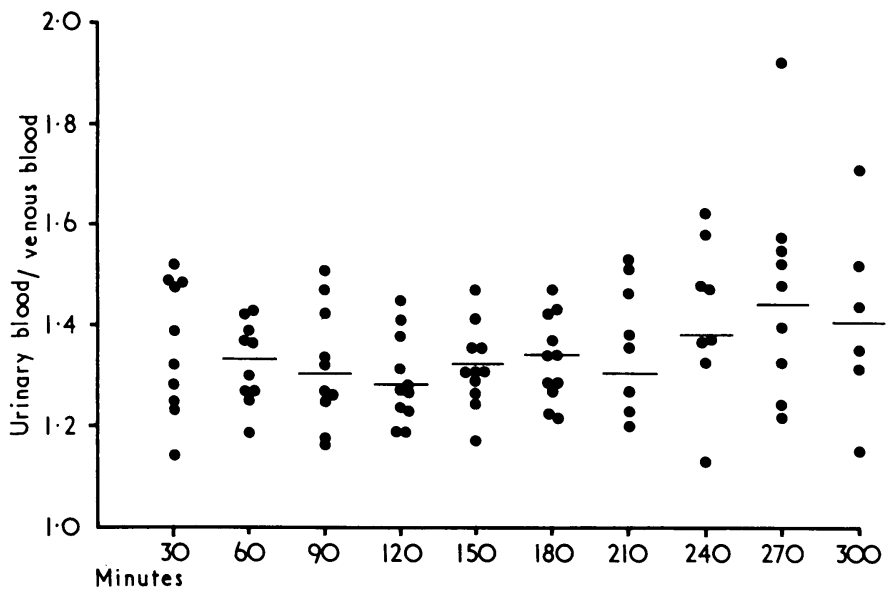

Fig. 2.-Individual and mean (horizontal line) urinary to venous blood alcohol concentration ratios at varying times after rapid infusion of ethanol. Average at 30 minutes would be meaningless, since in some cases urinary and venous blood levels had not crossed by this time.

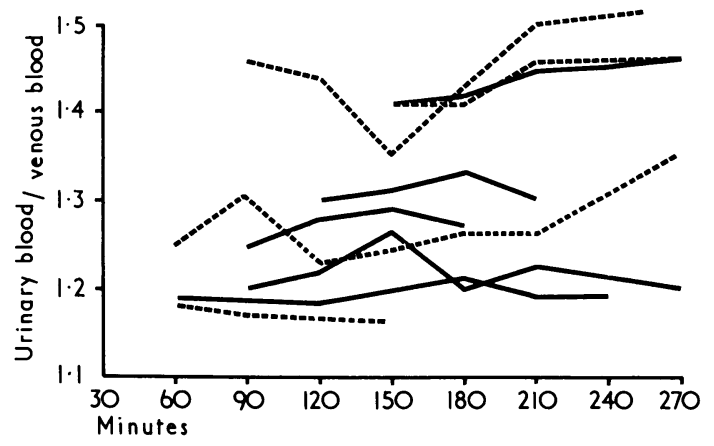

FIG. 3.-Individual ratios of urine to venous blood ethanol concentrations in patients who had (-) or had not (--) previous infusion of fluid.

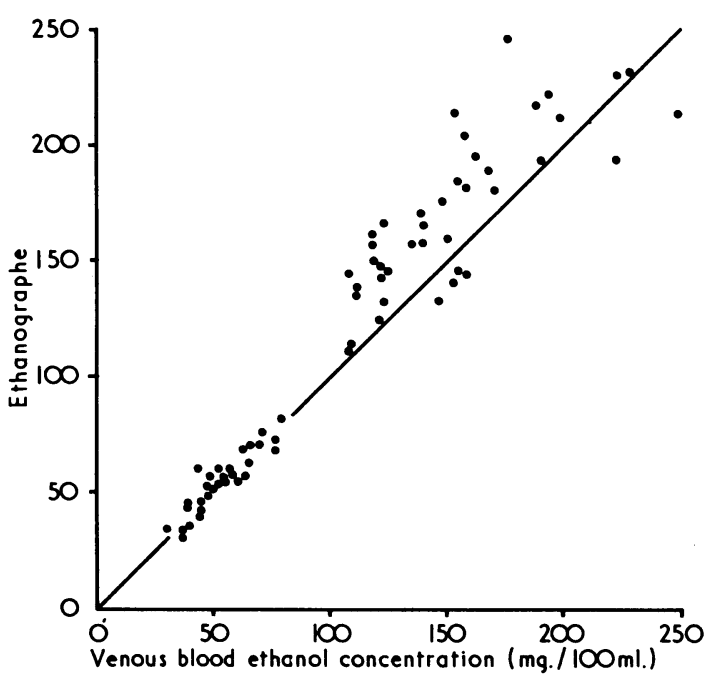

FIG. 4.-Relationship of venous blood ethanol concentration to concentration estimated from Ethanographe.

ratio in each patient over the period of 60 to 240 minutes is averaged they give a mean of 1.31 , with a range of 1.19 to 1.47 .

In Fig. 4 the breath readings are plotted as "estimated equivalent venous concentration as given by the Ethanographe" against actual venous concentrations. These show two patterns. During the recovery period with the low readings up to $80 \mathrm{mg} . / 100 \mathrm{ml}$. there was very good correlation between these two determinations. During anaesthesia by the rebreathing method employed in this study, however, breath analyses gave a higher estimation than was actually found in blood.

\section{Discussion}

These results show that there is an individual variation in response to intravenous infusion of ethanol with respect to the levels in venous blood and urine after a standard dose. This applies particularly to the urine concentration and to the time at which this exceeds the venous level. This variation could not be correlated with the prior hydration of the patients. With the exception of the expected earlier cross over after the administration of ethanol by the intravenous route, however, the mean values follow the pattern described by Drew, Colquhoun, and Long (1959), and Payne, Hill, and King (1966) after oral ethanol.

The variation in the urinary/venous blood ratios reported by many previous workers (Payne, Foster, Hill, and Wood, 1967) could be explained in part by the variable time interval between the two pairs of samples or failure to standardize the time from drinking (Hill, 1965). Drew et al. (1959) stressed the importance of prior emptying of the bladder on the findings, since the concentration in the bladder builds up more slowly than in venous blood (Wayne, 1963).

Our mean urinary/venous blood ratio of 1.35 was similar to that recorded by the special committee of the British Medical Association (1954) and the 1.38 reported by Payne et al. (1967) from the data of Morgan (1965), but was lower than the 1.42 from their own data, which were based on repeat urine and a single blood sample. Nothing was found approaching the 2.44:1 ratio reported in one subject by Payne et al. (1967).

The most important finding in this respect was the consistency of the ratio in individual subjects over a fairly long period of time (Fig. 3). The failure to find a correlation with hydration is at variance with the findings of Jetter (1941), who measured urinary specific gravity and found that it could be related in some degree to the urinary/venous blood ratio.

The Ethanographe is a machine which analyses a constant 
volume of breath sample at a constant temperature for ethanol concentration. By means of gears this result is transferred to a digital read out which gives the estimated equivalent venous blood level of ethanol. In contrast to the remainder of the United Kingdom, where a colour change (Alcotest Draeger) determines whether a breath sample contains more than the permitted limit corresponding to $80 \mathrm{mg}$. of ethanol per $100 \mathrm{ml}$. of blood, in Northern Ireland the Ethanographe is used to give a reading equivalent to the venous blood ethanol level.

With the Ethanographes currently used in this province there was an excellent correlation between actual and derived blood levels when these were below $80 \mathrm{mg} . / 100 \mathrm{ml}$. The high blood levels studied were above those for which these machines are normally used as a screening device by officers of the law. At this range (over $110 \mathrm{mg} . / 100 \mathrm{ml}$.) we found a higher estimated blood concentration than that in venous blood. In order to be sure of getting an alveolar gas sample for analysis during anaesthesia it was felt necessary to have the patient rebreathe for a period of two minutes. During this time there was a rapid fall in both arterial and venous blood and hence alveolar levels. A bag sample taken over a twominute period would therefore be drawn from a range of alveolar concentration at the beginning of which time the blood level would be much higher than at the actual time of venous blood sampling. Thus these discrepancies are most likely to arise from causes unassociated with the breathalysers.

The change in the gearing ratio in the Ethanographe from the original $58: 1$ to the currently used $67: 1$ obviously gives an increased accuracy, as shown in Fig. 4. On this basis the unmodified Ethanographe would be expected to give an unusually low estimation of venous ethanol concentration.

Our thanks are due to the medical and nursing staff of Musgrave Park Hospital for their co-operation in this study and to Dr. A. J. Howard, of the Forensic Laboratory, Ministry of Commerce, and Mr. J. Taggart, technician in the same department, for their co-operation. Our thanks are due also to Mr. P. J. Howard and other members of the staff of the department of anaesthetics. During the course of this study Dr. Isaac was in receipt of a Commonwealth Universities Research Fellowship.

REFERENCES

Borkenstein, R. F., and Smith, H. W. (1961). Medicine, Scienc and the Law,

British Medical Association (1954). Recognition of Intoxication. London, British Medical Association.

Drew, G. C., Colquhoun, W. P., and Long, H. A. (1959). Medical Research Council, Memorandum, No. 38, pp. 67, 68.

Dundee, J. W. (1970). Anesthesia and Analgesia Current Researches. In press. undee, J. W., Isaac, M., Pandit, S. K., and McDowell, S. A. (1970) British fournal of Anaesthesia, 42, 300.

Dundee, J. W., Isaac, M., and Taggart, J. (1970). Quarterly fournal of Studies on Alcohol. In press.

Gostomzyk, J. G., Dilger, B., and Dilger, K. (1969). Zeitschrift für klinische Chemie und klinische Biochemie, 7, 162

Gostomzyk, J. G., and Streffer, C. (1960). Blutalkohol, 6, 211

Hill, I. D. (1965). British Medical fournal, 1, 383.

Jetter, W. W. (1941). Ouarterly fournal of Studies on Alcohol, 2, 512

Morgan, W. H. D. (1965). Fournal of the Forensic Science Society, 5, 15.

Noordzij, P. C. (1969). Measuring devices and methods for determining blood alcohol concentration. Institute for Road Safety Research, (S.W.O.V.) Voorburg, Netherlands.

Payne, J. P., Foster, D. V., Hill, D. W., and Wood, D. G. L. (1967). British Medical fournal, 3, 819 .

Payne, J. P., Hill, D. W., and King, N. W. (1966). British Medical Fournal,

1, 196. 118. London, British Medical Association.

\title{
Benign Intracranial Hypertension following Corticosteroid Withdrawal in Childhood
}

\author{
B. G. R. NEVILLE, ${ }^{*} \ddagger$ M.B., B.S., M.R.C.P. ; J. WILSON, $†$ M.B., PH.D., M.R.C.P.
}

\begin{abstract}
Cummary: In an 18-month period seven children $\checkmark$ who were treated for a variety of neurological and non-neurological diseases, and in whom the corticosteroid or corticotrophin dosage was reduced, developed a syndrome indistinguishable from "benign intracranial hypertension." The total duration and rate of reduction of corticosteroid dosage and perhaps an underlying susceptibility to cerebral oedema appear to be important factors in this syndrome. Usually patients can be treated without the need for special neuroradiological studies. Possibly mild forms of this condition are not uncommon, but its pathogenesis is still uncertain.
\end{abstract}

\section{Introduction}

The syndrome of benign intracranial hypertension comprises headache and papilloedema occurring usually without focal neurological signs except occasionally a sixth-nerve palsy. Ventricular size is normal or small except in long-standing

\footnotetext{
- House-physician

† Consultant Neurologist. Department of Neurology, the Hospital for Sick Children, Great Ormond
Street, London W.C.1. ¥ Present address: National Hospital for Nervous Diseases, Queen Square,
London W.C.1.
}

cases, when some dilatation may occur. Though the condition is considered to be benign, some patients develop severe visual loss.

Benign intracranial hypertension has been reported in association with many conditions: (1) otitis media, possibly with lateral and sagittal sinus thrombosis (Symonds, 1952; Greer, 1962); (2) hypocalcaemia (Sugar, 1953); (3) administration of tetracycline (Fields, 1961), nalidixic acid (Boréus and Sundström, 1967), and vitamin A (Gerber et al., 1954); (4) primary Addison's disease (Jefferson, 1956); (5) reduction of corticosteroid dosage (Dees and McKay, 1959; Greer, 1963a). (6) Greer (1963b), described the occurrence of this syndrome at between the second and fifth months of pregnancy, at menarche (Greer, 1964a), and in secondary amenorrhoea (Greer, 1964b), and discussed the hypothesis that falling levels of circulating corticosteroid and rising levels of oestrogen are important factors in its pathogenesis.

The association of corticosteroid administration and benign intracranial hypertension was first suggested by Freyberg et al. (1957), and further independent reports followed (Dees and McKay, 1959; Valentine, 1959). These are mainly of children, and except for some of the earliest reports (Valentine, 1959; Laurence et al., 1960) this has always followed reduction of the dose of corticosteroids (Greer 1963a).

The clinical presentation was similar to that seen in other 